\title{
PENICILLIN SENSITIVITY OF STREPTOCOCCI ISOLATED FROM ROOT CANAL INFECTIONS AND THE NORMAL MOUTH ${ }^{1}$
}

\author{
MARY C. CROWLEY, M.S.P.H., AND VERNA HARNER, B.S. \\ School of Dentistry, University of Michigan, Ann Arbor, Mich.
}

Many workers have shown that certain strains of supposed penicillin-sensitive bacteria may be resistant to penicillin. Since a clinical study of the effect of penicillin in infected root canals was contemplated it was thought desirable to ascertain the sensitivity of individual strains of streptococci, which are the organisms commonly isolated from infected root canals. At the same time it was decided to determine the reactions to penicillin of streptococci from saliva of normal mouths. As it has been presumed that the streptococci causing root canal infections are usually derived from the saliva, the reactions of streptococci from the two sites might lead to some information on their relationship.

Material from infected root canals was inoculated into beef infusion semi-solid agar, containing ascitic fluid. The cultures after incubation at $37.5^{\circ} \mathrm{C}$. for $36-48$ hours were plated out on $2 \%$ blood agar. Single colonies of streptococci were then transferred to other blood agar plates to be studied. The reaction on blood was determined, and the streptococci classified as hemolytic, viridans or anhemolyticus. No other method or classification was attempted, since the viridans and anhemolytic types form such heterogenous groups that it was not thought expedient at this time to attempt further classification. The hemolytic group of streptococci are recovered in only $2 \%$ of infected root canals.

Streptococci from saliva were obtained from individuals who had no mouth infections. The saliva after collection was diluted with physiological salt solution, so that discrete colonies grew when streaked on blood agar. Single colonies were transferred to blood agar for study. No difficulty was encountered in identifying viridans type of streptococci, but difficulty was encountered with hemolytic and anhemolytic types of streptococci. It was noticed that colonies which had been picked as hemolytic types after replating, were anhemolytic in type; or that the anhemolytic type was hemolytic. At first it was thought that errors had been made in identifying colonies, but it happened so frequently, and after further precautions had been taken that we realized that we were dealing with dissociated strains, which had to be replated several times to obtain pure phase cultures. This particular problem is to be investigated in the near future.

Tryptose broth (1) containing $5 \%$ ascitic fluid, and penicillin sodium was used to carry out the penicillin sensitivity tests. Strains were tested in $0.03 \mathrm{U}, 0.5$ $\mathrm{U}$. and $8 \mathrm{U}$. of penicillin per c.c. of broth. A positive control was made in the

1 Read at the 25th General Meeting of the International Association for Dental Research, Chicago, June 21-22, 1947. (J.D. Res. $26: 455,1947)$. Received for publication July 7, 1947 . 
same amount of broth, containing no penicillin. Each of the 4 tubes was then inoculated with 0.2 c.c. of an 18-24 broth culture. An especially penicillin-sensitive strain of Streptococcus dysgalactiae was used to inoculate the negative controls, which were always made with each set of tests. All tests were read after incubation at $37.5^{\circ} \mathrm{C}$. for $18-24$ hours.

The broth cultures from which inoculations were made, were plated out after tests were made to be sure no contamination or type changes had occurred.

If no growth occurred in any of the tubes containing penicillin, or if growth occurred only in the tube containing $0.03 \mathrm{U}$. per c.c. of penicillin, the strain was considered sensitive to penicillin. If growth occurred in both of the tubes containing $0.03 \mathrm{U}$. and $0.5 \mathrm{U}$. per c.c., and as sometimes was the case in the tube containing $8 \mathrm{U}$. per c.c., the strain being tested was considered resistant.

Tests were also read after $48-72$ bours incubation but since the negative control

TABLE I

Penicillin in vitro reactions of streptococci

\begin{tabular}{|c|c|c|c|c|c|c|c|c|c|c|c|c|c|c|c|}
\hline \multirow{3}{*}{$\begin{array}{c}\text { BOURCE OF } \\
\text { BTRRPTOCOCOH }\end{array}$} & \multicolumn{5}{|c|}{ Strep. viridans } & \multicolumn{5}{|c|}{ Strep. ankemolyticus } & \multicolumn{5}{|c|}{ Strep. hemolyticus } \\
\hline & \multirow{2}{*}{ 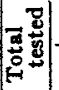 } & \multicolumn{2}{|c|}{ Resistant } & \multicolumn{2}{|c|}{ Sensitive } & \multirow{2}{*}{ 焉 } & \multicolumn{2}{|c|}{ Resistant } & \multicolumn{2}{|c|}{ Sensitive } & \multirow{2}{*}{ 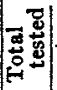 } & \multicolumn{2}{|c|}{ Resistant } & \multicolumn{2}{|c|}{ Sensitive } \\
\hline & & No. & $\%$ & No. & $\%$ & & No. & $\%$ & No. & $\%$ & & No. & $\%$ & No. & $\%$ \\
\hline \multirow[t]{2}{*}{ Root } & \multirow[b]{2}{*}{82} & \multirow{2}{*}{\multicolumn{2}{|c|}{9 or 10.9}} & \multirow{2}{*}{\multicolumn{2}{|c|}{73 or 89.1}} & \multirow[b]{2}{*}{9} & \multirow{2}{*}{\multicolumn{2}{|c|}{77 or 87.5}} & \multirow{2}{*}{\multicolumn{2}{|c|}{11 or 12.5}} & & & & & \\
\hline & & & & & & & & & & & 10 & \multicolumn{2}{|c|}{9 or 90} & \multicolumn{2}{|c|}{1 or 10} \\
\hline Saliva. & 26 & \multicolumn{2}{|c|}{3 or 11.6} & \multicolumn{2}{|c|}{23 or 88.4} & 13 & \multicolumn{2}{|c|}{3 or 23,1} & \multicolumn{2}{|c|}{10 or 76.9} & 21 & \multicolumn{2}{|c|}{0 or 0} & \multicolumn{2}{|c|}{21 or 100} \\
\hline
\end{tabular}

containing $0.03 \mathrm{U}$. per c.c. of penicillin also grew the sensitivity of the organisms to penicillin was determined from the 24 hour reading.

\section{RESULTS}

Eighty-two strains of Streptococcus viridans were isolated from infected root canals (Table I). Of these only $9(10.9 \%)$ were resistant to penicillin, while 73 $(89.1 \%$ ) were sensitive. Three $(11.6 \%)$ of the 26 strains of Streptococcus viridans isolated from saliva were resistant, while $23(88.4 \%)$ were sensitive. Statistical tests $^{2}$ showed that this small observed difference in penicillin sensitivity between Streptococcus viridans from the 2 sources was due to chanceal one. Eightyeight strains of Streptococcus anhemolyticus were isolated from infected root canals. Seventy-seven $(87.5 \%)$ were resistant, while only $11(12.5 \%)$ were sensitive. This is in marked contrast to the reactions of the Streptococcus viridans from the same source, and also Streptococcus anhemolyticus isolated from saliva. Only 13 strains of Streptocuccus anhemolyticus from saliva were tested, of these $3(23.1 \%)$ were resistant while $10(76.9 \%)$ were sensitive. These differences were found to be quite highly statistically significant, even on the basis of as small a sample as 13. This study, though limited in scope, does indicate a real difference

2 Miss Mabel Tramp, statistician at the School of Public Health, University of Michigan, made all the statistical studies. 
in the reactions of the anhemolytic streptococci from infected root canals and saliva.

Only 10 strains of hemolytic streptococci were isolated from root canals. Nine $(90 \%)$ of these were resistant. Only one $(10 \%)$ was sensitive. Twenty-one strains of hemolytic streptococci were isolated from the saliva. All of these were sensitive. There were no resistant strains found in this group. This $0 \%$ presented some difficulty in applying a statistical test. However, it can be proved that a $0 \%$ based on a sample of 21 , by chance alone, could have been as much as $10 \%$ or possibly even $15 \%$. Even if as much as $15 \%$ instead of none of the 21 strains of hemolytic streptococci isolated from saliva had been sensitive, which could have happened merely by chance, the difference would still have been quite highly significant. A real difference is indicated by this experiment, in the reactions of hemolytic streptococci isolated from infected root canals and those isolated from saliva.

The results of 48 hour incubation of the streptococci isolated from root canals were interesting. Only $3(3.6 \%)$ of the 82 strains of Streptococcus viridans grew in $8 \mathrm{U}$. of penicillin per c.c. after 48 hours incubation. None grew in 24 hours. Thirty $(34 \%)$ of the 88 strains of Streptococcus anhemolyticus grew in $8 \mathrm{U}$. of penicillin after 48 hours incubation. Twelve (13.6\%) grew after 24 hours. Three $(30 \%)$ of the 10 strains of Streptococcus hemolyticus grew after 48 hours incubation. None of then grew after 24 hours.

None of the streptococci isolated from saliva grew in $8 \mathrm{U}$. of penicillin per c.c. at any time.

\section{CONCLUSIONS}

From these experiments it may be concluded that Streptococcus viridans from root canals is sensitive to penicillin. Anhemolytic and hemolyticus streptococci from root canals are resistant to penicillin.

The necessity of testing various strains to determine penicillin sensitivity is obvious.

Streptococcus viridans from infected root canals and saliva seem to be similar in relation to penicillin sensitivity.

The anhemolytic streptococci and hemolytic streptococci from infected root canals, and those from saliva are markedly different in their reactions to penicillin. However, further study is definitely recommended.

These differences may serve as a method, or at least give a clue to a method, for classifying the anhemolytic group of streptococci. Bornstein (2) used penicillin sensitivity to classify some types of streptococci. He reported "the method checks well with differentiations which have been made on a basis of physiological studies."

The results of these experiments lead one to doubt that the anhemolyticus and hemolytic streptococci from infected root canals are the same as those found predominating in the mouth.

\section{REFERENCES}

1. Kakavas, V. C., ANd Scott, E. G., Science, 104:327-328, 1946.

2. Bornstein, S., J. Bact., 39: 383-387, 1940. 